Brit. Heart F., 1967, 29, 367.

\title{
Assessment of Site and Severity in Congenital Aortic Stenosis
}

\author{
CELIA M. OAKLEY^ AND K. A. HALLIDIE-SMITH
}

\author{
From the Department of Medicine (Clinical Cardiology), Hammersmith Hospital, and Postgraduate Medical School \\ of London W.12
}

It has frequently been stated that congenital aortic valve stenosis cannot be distinguished with any confidence from discrete subvalvar aortic stenosis on clinical grounds, and that their separation rests on the results of hæmodynamic investigation and angiocardiography (Nadas, 1957; Ongley et al., 1958; Dotter et al., 1961; Braunwald et al., 1963; Engle and Ehlers, 1964). Our experience has led us to the opposite conclusion. We believe that the distinction may nearly always be made clinically with considerable assurance and is based on reliable differences in the auscultatory characteristics to which we have previously called attention (Oakley, Hallidie-Smith, and Bentall, 1964). Hancock (1961), Engle and Ehlers (1964), Gamboa, Hugenholtz, and Nadas (1964), Epstein et al. (1965), Raftery (1965), and Vogel and Blount (1965) have all emphasized the importance of the early systolic click in aortic valve stenosis. Vogel and Blount also confirmed our finding that the closure sound of the aortic valve is soft in discrete subvalvar aortic stenosis and normal or of increased intensity in aortic valve stenosis. The purpose of this report is to relate these auscultatory differences to the hæmodynamic differences between the two major types of congenital aortic stenosis and to left ventricular obstruction associated with hypertrophic cardiomyopathy.

Clinical judgement of the severity of congenital aortic stenosis also presents a problem: the arterial pulse, the length of the obstructive murmur, and the assessment of left ventricular hypertrophy, all being misleading on occasions. Some auscultatory characteristics which might be more consistently related to the amount of obstruction were therefore also studied.

Received June 15, 1966.

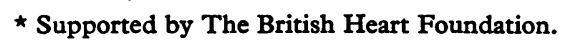

\section{The Patients}

Forty patients with congenital aortic valve stenosis under the age of 30 years, and 21 patients with discrete subvalvar aortic stenosis have been studied; the number excludes patients who had aortic stenosis associated with other intracardiac defects. The ages of the patients ranged between 4 and 29 years in those with valve stenosis and between 3 and 44 years in those with discrete subvalvar stenosis. Thirty-three of the patients with valvar stenosis and all 21 patients with discrete subvalvar stenosis required surgical relief and 52 of the 54 patients were treated by open operation under cardiopulmonary bypass. No patients have been included who were studied before 1961, and phonocardiograms were available in all for correlation with the clinical auscultatory findings.

Two patients with discrete subvalvar aortic stenosis died without operation; one suddenly, having refused admission some weeks earlier, and one who was flown in from abroad with terminal bacterial endocarditis. Their hearts and the hearts of three other patients with discrete subvalvar stenosis who died after operation were examined at necropsy. Necropsy was also carried out on the only patient with valvar aortic stenosis to die, a 9-year-old boy with a hypoplastic aortic ring who died 5 months after unsuccessful relief of the obstruction. Forty-seven patients were followed up for between 1 and 5 years after operation and post-operative hæmodynamic studies were carried out in $\mathbf{4 0}$ of these.

\section{Clinical Findings}

Aortic Valve Stenosis in Patients Aged Under 30 Years. All 40 patients with aortic valve stenosis had an aortic valve opening sound or click which introduced the stenotic murmur, and in all of them aortic valve closure was of normal intensity or even louder than normal (Fig. 1A). These loud valve opening and closure sounds could easily be appreciated clinically and were not simply phonocardiographic phenomena. The stenotic aortic valve was competent in the majority of patients, but some 


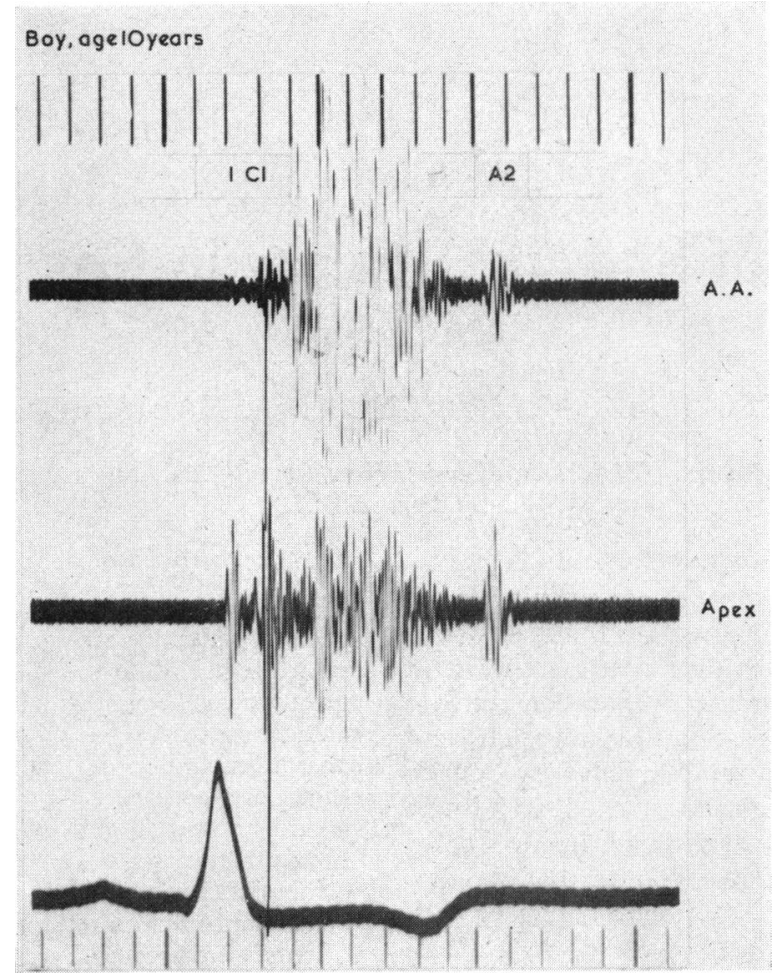

FIG. 1A.-Phonocardiogram in typical young patient with aortic valve stenosis. The click (Cl) follows $0.05 \mathrm{sec}$. after mitral valve closure (1) and $0.1 \mathrm{sec}$. after the $Q$ of the electrocardiogram. Aortic valve closure $\left(A_{2}\right)$ is loud and both $\mathrm{Cl}$ and $\mathrm{A}_{2}$ are better heard at the apex than in the aortic area (A.A.).

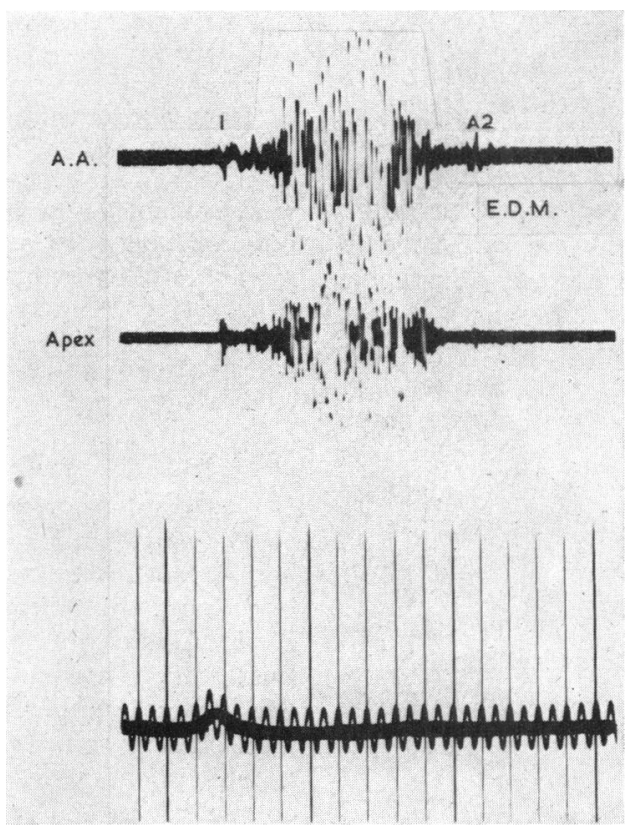

FIG. 1B.-Typical auscultatory findings in discrete subvalvar aortic stenosis. $A_{2}$ is soft and delayed or unrecordable. A click can usually not be recorded and in the two patients in whom a soft click was recorded it could not be heard even though specifically listened for. A soft early diastolic murmur (E.D.M.) is also seen. 


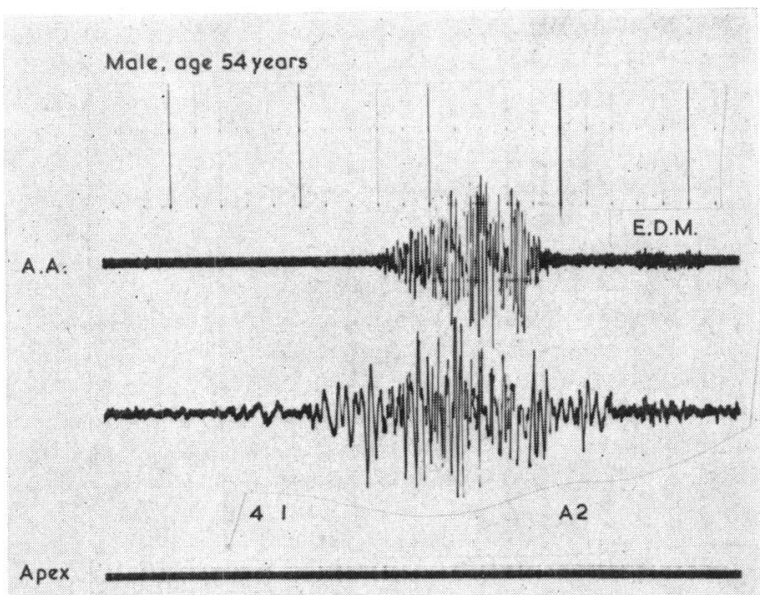

FIG. 1c.-In calcific aortic stenosis the phonocardiogram is similar to that in discrete subaortic stenosis. The atrial beat (4) is prominent and was always recordable in the older patients with significant aortic stenosis.

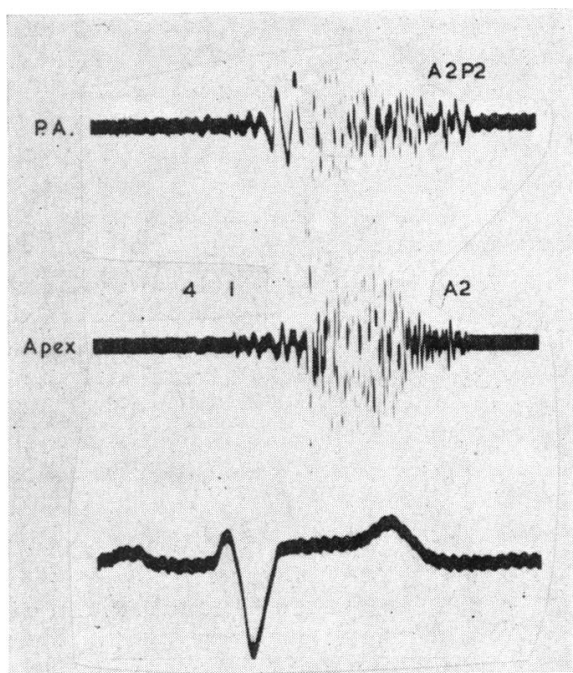

FIG. 1D.-In hypertrophic obstructive cardiomyopathy the atrial beat tends to dwarf the first sound and so makes the late systolic murmur sound even later in onset than it really is. $A_{2}$ is of normal intensity and no early diastolic murmur is heard. incompetence was detected either as an early diastolic murmur or by aortography in 15 of the 40 patients.

The ejection click was best heard at the apex where early in our experience it was sometimes mistaken for a loud first sound. The first sound was often soft in these patients. In other cases the cadence of the first sound and click, or of an atrial sound and click gave rise to a "split first sound" at the apex. The click occurred $0.05 \mathrm{sec}$. after the first sound and 0.09 to $0.1 \mathrm{sec}$. after the $Q$ wave of the electrocardiogram, and its timing was unrelated to the severity of the stenosis. The intensity of aortic valve closure was also best appreciated at the cardiac apex and its loudness made the respiratory variation of the two components of the second heart sound particularly easy to elicit at the left sternal edge or pulmonary area (Fig. 2).

Discrete Subaortic Stenosis. An ejection click was not audible in any of the patients with lone discrete subvalvar stenosis. Not only was opening of the aortic valve inaudible in these patients but closure of the valve was abnormally soft or inaudible also, and the obstructive murmur was heard as a "suspended" bruit without introductory click or concluding closure sound (Fig. 1B). Again, the diminished intensity of the aortic valve closure sound was best appreciated at the cardiac apex where it was either very soft or even absent. This frequently made appreciation of the relation of aortic and pulmonary valve closure impossible to assess clinically. Even pulmonary valve closure was often remote, for these patients usually had severe stenosis with prolonged left ventricular ejection and obstructive murmurs which. spilled through and obscured the sound of pulmonary valve closure.

Early diastolic murmurs were heard, or aortic regurgitation was shown on retrograde aortography, in all but 3 of the patients with discrete subvalvar stenosis. The other 3 patients had no audible early diastolic murmur and aortography was not carried out.

The aortic valve was found to be abnormal in only 3 of the patients with discrete subvalvar aortic stenosis. One of these was a boy with an associated bicuspid aortic valve, while the other two had 

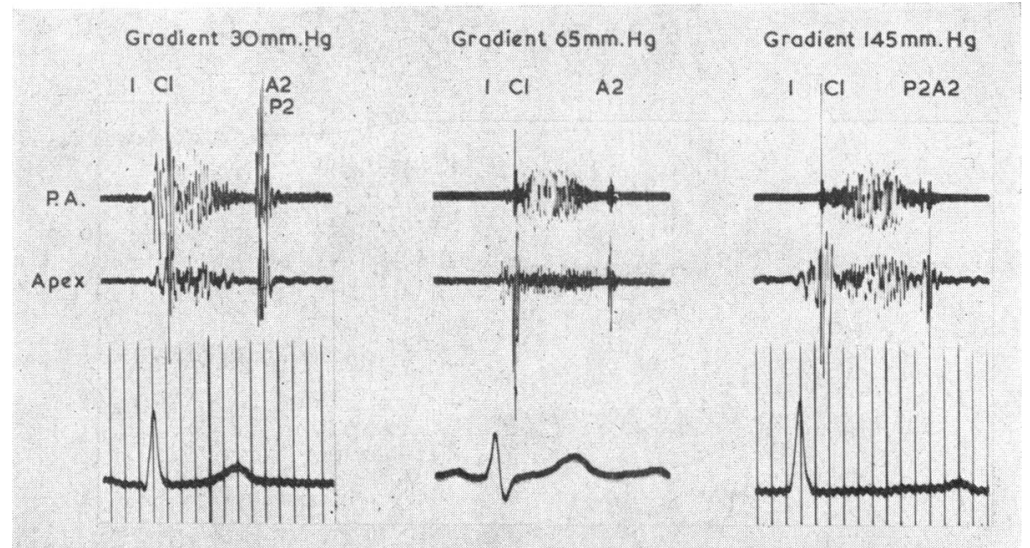

FIG. 2.-The timing of $A_{2}$ is easy in juvenile aortic valve stenosis because it is loud. It is always normal in mild stenosis, shown on the left. In more severe obstruction $A_{2}$ may be delayed with respect to $P_{2}$, but the correlation with severity is poor. The position of the peak of the murmur can be related to the gradient across the valve. Thus, maximum intensity of the murmur falls in the first half of systole in mild stenosis, in mid-systole in moderate stenosis, and in late systole in severe stenosis (see also Fig. 9).

damaged aortic valves with cusp perforations resulting from subacute bacterial endocarditis. In all the others the valve was found by the surgeon at operation to be normal; in four patients the normal valve cusps were very slightly thickened but this thickening was interpreted as a jet lesion which was not thought to be enough to impair its mobility or normal function.

The patient with discrete subvalvar stenosis associated with a bicuspid stenotic aortic valve had a loud ejection click, an audible but soft aortic closure sound, and an early diastolic murmur.

These auscultatory characteristics of discrete aortic stenosis were strikingly similar to those of older adults with calcific aortic valve stenosis, but differed from those in patients with muscular obstruction to left ventricular outflow associated with hypertrophic cardiomyopathy.

Calcific Aortic Valve Stenosis. In the older patients with aortic valve stenosis, ejection clicks were rare, aortic closure was soft or inaudible, and aortic incompetence was nearly always present in some degree though often underestimated clinically (Fig. 1C). These differences in auscultatory findings between aortic valve stenosis in youth and in later life were associated with invariable calcification of the abnormal aortic valve after the age of 40 years. Among the first 50 patients with lone aortic valve stenosis over the age of 40 years who were treated surgically, ejection clicks were present in only two and these two were also unusual in having normally audible aortic closure sounds. Aortic valvotomy was possible for the two patients with audible aortic valve opening and closing sounds, whereas in all the other patients gross calcification and fibrosis with consequent immobilization and disorganization of the valve made prosthetic replacement necessary.

Hypertrophic Cardiomyopathy. In hypertrophic obstructive cardiomyopathy the onset of the murmur was characteristically delayed and sometimes did not commence until as long as 0.1 sec. after mitral valve closure. In others it started early but tended to have a late systolic peak, and in most cases predominance of the atrial sound distracted attention from the subsequent first sound and made the systolic murmur appear to commence later in systole than it actually did (Fig. 1D). The murmur tended to be shorter than in organic stenosis and the atrial sound was disproportionally prominent. No patient with hypertrophic obstructive cardiomyopathy had an aortic diastolic murmur, and an aortic ejection click was heard in only one.

\section{Hamodynamic Studies}

The severity of the left ventricular obstruction was estimated by measurement of the left ventricular-aortic pressure gradient; the left ventricle was entered retrogradely from the aorta, or antegradely percutaneously, or after transseptal catheterization of the left atrium.

The site of the left ventricular obstruction was identified by aortography or left ventricular angiography or both. Either the 6/sec. biplane ElemaSchönander roll film changer, or $35 \mathrm{~mm}$. 38 
frame/sec. cinefluorography, or both, were employed.

Besides revealing the presence and amount of aortic valve reflux, aortography was employed to demonstrate the thickness and mobility of the aortic valve cusps, the width of the emergent jet of non-opacified blood from the left ventricle, and the anatomy and calibre of the coronary arteries (Fig. 3).

In young patients with aortic valve stenosis the number and symmetry of the aortic sinuses, and the position and width of the jet through the stenotic valve orifice were usually readily appreciated. As the valve opened, the cusps inverted from their normal concave form to an upward domed position which coincided with the click on the phonocardiogram and the cross-over of the left ventricular and aortic pressures at the commencement of ejection. Valve closure was prompt and usually competent or associated with only mild regurgitation.

In the patients with discrete subvalvar stenosis the normal aortic valve moved quite abnormally. It appeared rigid and incompetent on aortography, neither opening fully nor closing decisively. Cineaortography was particularly revealing, showing a delayed sudden movement into the half-open position in these patients. Sometimes a jet was seen as in valve stenosis, but in contrast to valve stenosis where the jet emerged from the summit of the dome, the jet in subvalvar stenosis traversed a valve with straight or concave cusps which had not moved into the fully open position (Fig. 4A).

Pressure records showed the reason for this. Pressure changes in the body of the left ventricle were not immediately communicated to the subvalvar zone and valve cusps through the subvalvar stricture. The systolic rise of pressure in the subvalvar zone was sometimes delayed. Similarly, the fall in pressure with commencing relaxation was delayed in the subvalvar zone, and the dicrotic notch of the central aortic pressure pulse was late and occurred up to $0.04 \mathrm{sec}$. after the left ventricular cavity and aortic pressures had crossed (Fig. 5). Retrograde aortography revealed mild to moderate reflux of contrast through the valve into the left ventricle, and occasionally the opacification of the left ventricle was sufficient for the subaortic obstruction to be visualized holding up the regurgitant stream in diastole and preventing further dilution of the contrast with the major portion of the left ventricular contents (Fig. 6).

Delay of aortic valve closure as timed by the position of the dicrotic notch of the central aortic pressure trace in relation to the pressure cross-over was also observed in calcific valve stenosis but not in non-calcific valvar stenosis. In our experience some regurgitation is almost invariable when the aortic valve is heavily calcified, and, indeed, if a valve is virtually immobile survival necessitates this.

\section{AsSESSMENT OF SEVERITY}

We have seen children with severe aortic stenosis who had an arterial pulse of normal volume, and we have investigated children with trivial stenosis because their pulses were of small volume. Like Nadas and his colleagues (Reynolds et al., 1960), we have found that a normal electrocardiogram does not exclude severe aortic stenosis, though an abnormal one with ST-T wave changes excludes mild stenosis. Sudden death from severe aortic stenosis has been reported in children with a normal electrocardiogram (Braverman and Gibson, 1957; Kjellberg et al., 1959), though it is rare and in most of the reported cases there have been either symptoms or electrocardiographic changes (Lees et al., 1962). On the other hand, accepted voltage criteria of left ventricular hypertrophy without ST-T changes may be met in children with trivial stenosis, as they may also in children with normal hearts (Fig. 7). Like Braunwald and his colleagues (1963), we found no correlation between the radiological size of the left ventricle and the gradient or orifice size at operation, neither did we find any correlation between the presence or absence of prominence of the ascending aorta and the site or severity of stenosis (Fig. 8).

The Cardiac Impulse. As with the electrocardiogram, unequivocal evidence of left ventricular enlargement indicated severe stenosis, but we overestimated severity in several children with vigorous apical impulses. A presystolic atrial sound is a common normal finding in children and does not have significance unless it is readily palpable and recordable on the impulse cardiogram. Absence of a presystolic impulse did not, however, exclude severe stenosis.

The Phonocardiogram. When the length of left ventricular systole (Fig. 9A) and the duration of the obstructive murmur (Fig. 9B) were related to the left ventricular-aortic gradient no correlation was found, and the only useful characteristic of the murmur was the position of its peak. Fig. 9C shows the timing of the peak of the murmur against the obstructive gradient, and it can be seen that the later the peak the more severe is the stenosis. Thus, a long murmur when it occurred in some cases of mild stenosis had an early peak, whereas delay in reaching maximum intensity always indicated severe stenosis (Fig. 2). 


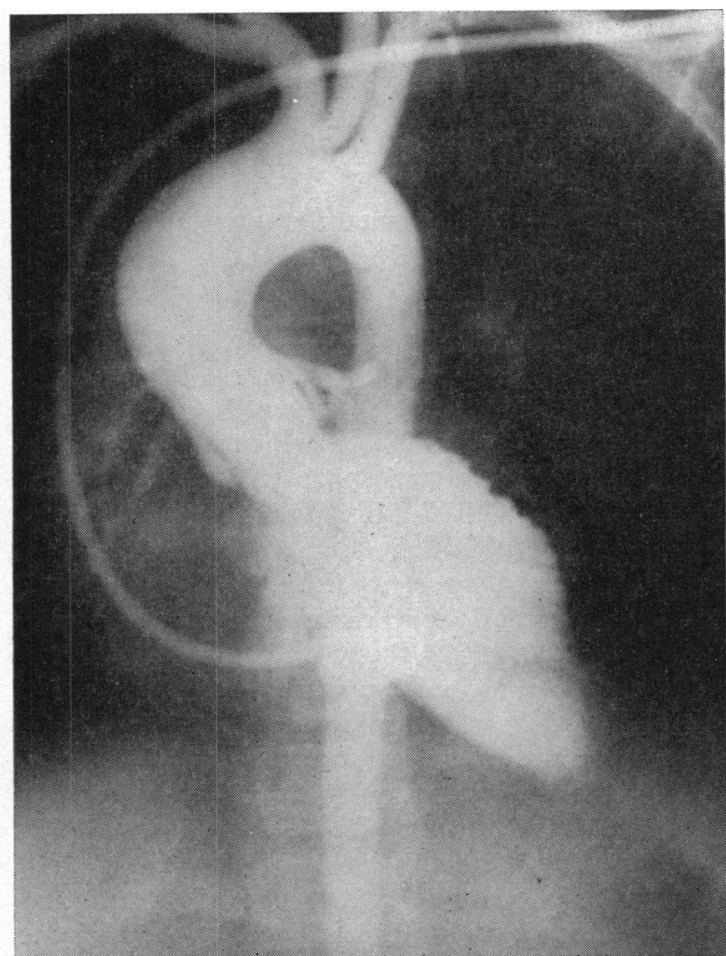

Fig. 3A.-Frontal view left ventricular angiogram to show the appearance of the normal aortic valve during the ejection phase (the catheter was passed through an atrio-ventricular canal defect).

Reversed splitting of the second heart sound was heard occasionally in patients with gradients of 50 $\mathrm{mm}$. $\mathrm{Hg}$ and over, but a normal disposition of the aortic and pulmonary components was found in some patients with the most severe obstruction. Reversed splitting sometimes developed only on exercise when a rise in stroke output in moderate stenosis resulted in an increase in left ventricular pressure and prolongation of left ventricular ejection.

\section{Discussion}

The loud valve opening and closure sounds heard in young subjects with aortic valve stenosis are related to decisive opening and closing movements of an abnormal but mobile valve. Later in life calcification of abnormal valves determines their progressive fixation. The opening and closure sounds disappear, and, with immobility, obstruction must tend to increase and incompetence is likely to develop. The auscultatory findings are now similar to those of discrete subaortic stenosis, and immobility of the valve is the reason in both, though in the one condition the valve itself is normal and in

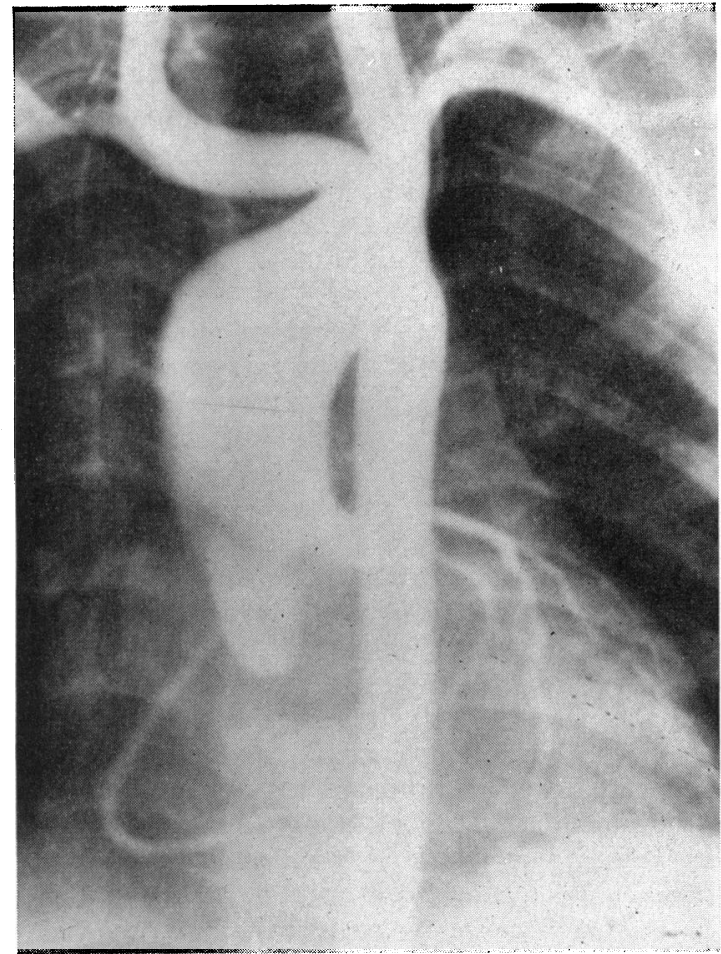

FIG. 3B.-Frontal view aortogram from a 6-year-old girl with aortic valve stenosis and a gradient of $100 \mathrm{~mm}$. $\mathrm{Hg}$, also taken during the ejection phase. The valve is domed up, a narrow jet emerges from the summit of the dome and hits the lateral wall of the aorta in the usual site of the post-stenotic dilatation.

the other it is petrified.

Similarly, in the patients with aortic valve stenosis the valve cannot be rendered normal by operation; some gradient usually remains and so do the click and murmur. A loud aortic ejection click may sometimes be heard in children who have no pressure gradient across the aortic valve. Occasionally the click is followed by quite a prominent murmur and has led to further investigation. These auscultatory findings indicate an abnormal aortic valve with unequally divided cusps or only two cusps, so that one cusp is stretched across the diameter of the aortic ring, cannot open fully, and domes up in systole with an audible click. The cine-angiographic appearance of this mechanism has been fully described by Ross and Criley and their colleagues (Epstein et al., 1965).

The disappearance of the early systolic click when the aortic valve calcifies and becomes immobile in later life surely finally answers the controversy between those who believe that the sound is produced in the valve as it opens (Arrigalla and Taquini, 1941; Wolferth and Margolies, 1945; 


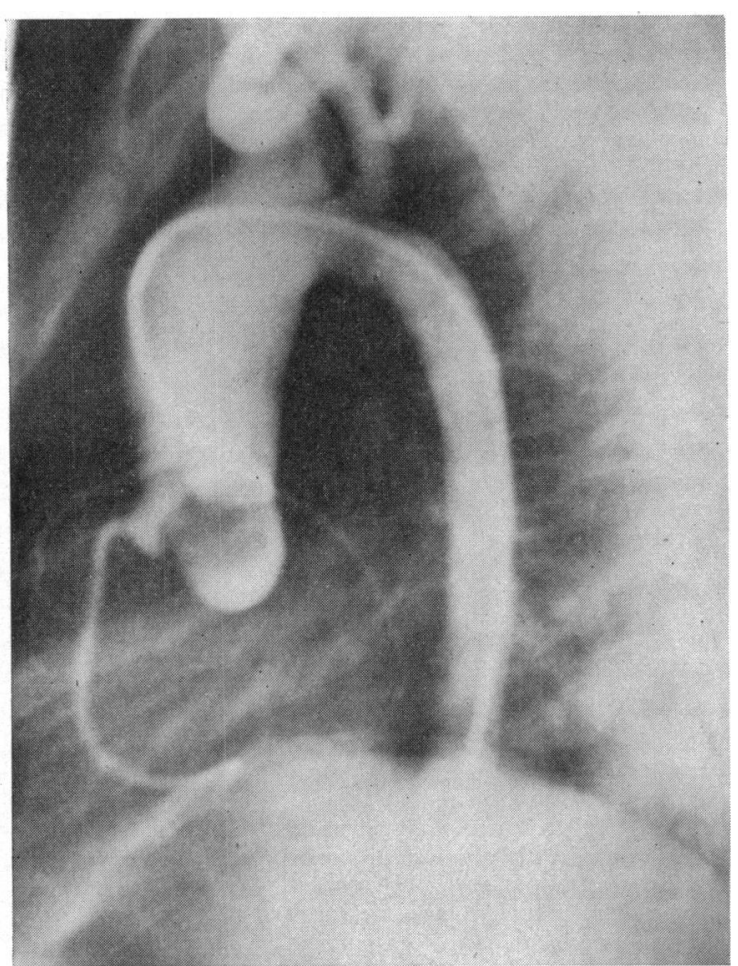

FIG. 3c.-Lateral systolic view of the same patient as in Fig. $3 \mathrm{~B}$, showing that the 3 aortic sinuses are of unequal size. The non-coronary sinus is abnormally large while the right anterior and left posterior sinuses are abnormally poorly developed.

Minhas and Gasul, 1959; Hancock, 1961) and those who believe that it is produced in the aortic wall (Leatham and Vogelpoel, 1954; Reinhold and Rudhe, 1957; Braunwald et al., 1963).

The hesitant opening and delayed and incompetent closure of the normal aortic valve in discrete subaortic stenosis is very different from the normal valve movement found in patients with muscular obstruction to left ventricular outflow associated with hypertrophic obstructive cardiomyopathy in which left ventricular pressure changes are freely communicated to the normal valve whose opening is therefore not delayed. In hypertrophic obstructive cardiomyopathy, as in the normal subject, aortic valve opening may contribute to the late components of the first heart sound and is not separable as a click. Unlike discrete subaortic stenosis, obstruction is absent in hypertrophic obstructive cardiomyopathy in diastole so the aortic valve closes audibly and competently.
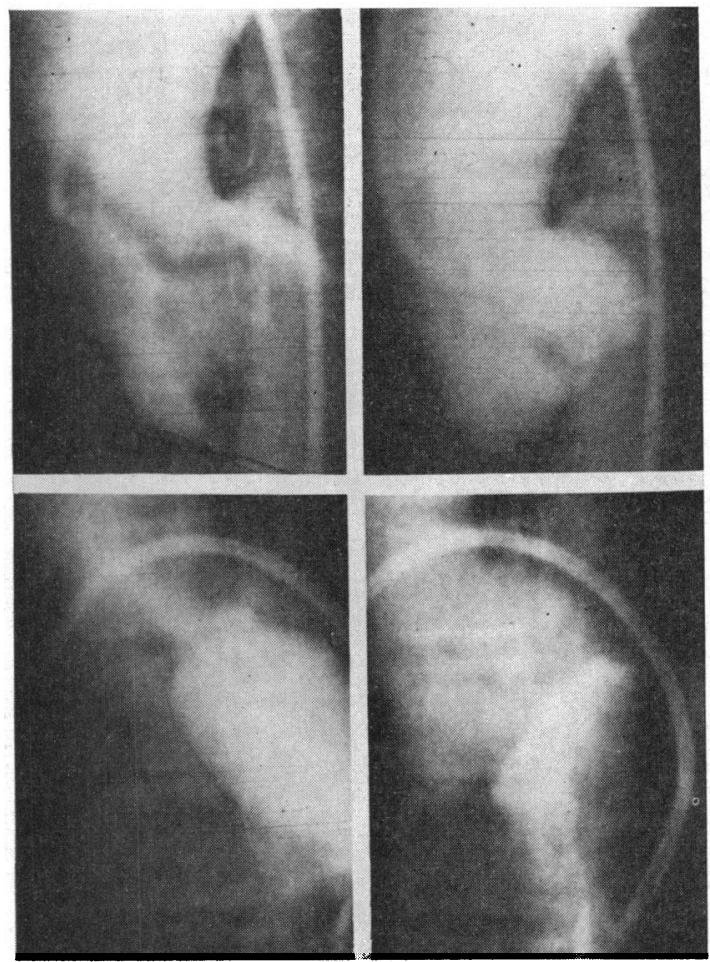

FIG. 3D.-Frontal views of the aortic valve from an 11-yearold girl with aortic valve stenosis and a gradient of $110 \mathrm{~mm}$. $\mathrm{Hg}$ across the obstruction. In the top two pictures contrast had been injected above the valve into the aorta and in the bottom two the contrast had been injected into the left ventricle. The extreme mobility of the valve between systole (on the left) and diastole (on the right) is well seen. The size of the orifice is indicated by the width of the jet emerging from the summit of the domed valve.

The occurrence of an early diastolic murmur in patients with discrete subaortic stenosis is well known and has been attributed to a number of different causes. Progressive damage of an intrinsically normal aortic valve by the jet through the subvalvar stricture has been suggested. Only four of our patients showed any visible evidence of thickening which might have been caused in this way, yet the patients with strictly normal undamaged valves also showed incompetence. Damage by subacute bacterial endocarditis with the infection settling on this jet lesion or spreading from the stricture beneath has also been invoked, yet only two of our patients showed evidence of valve damage from this cause. Post-stenotic dilatation of the region distal to the localized subvalvar stricture involving the valve ring and leading to failure of apposition of the valve cusps is a possible cause of incompetence. Such dilatation is rather characteristic of discrete subaortic stenosis and was well 


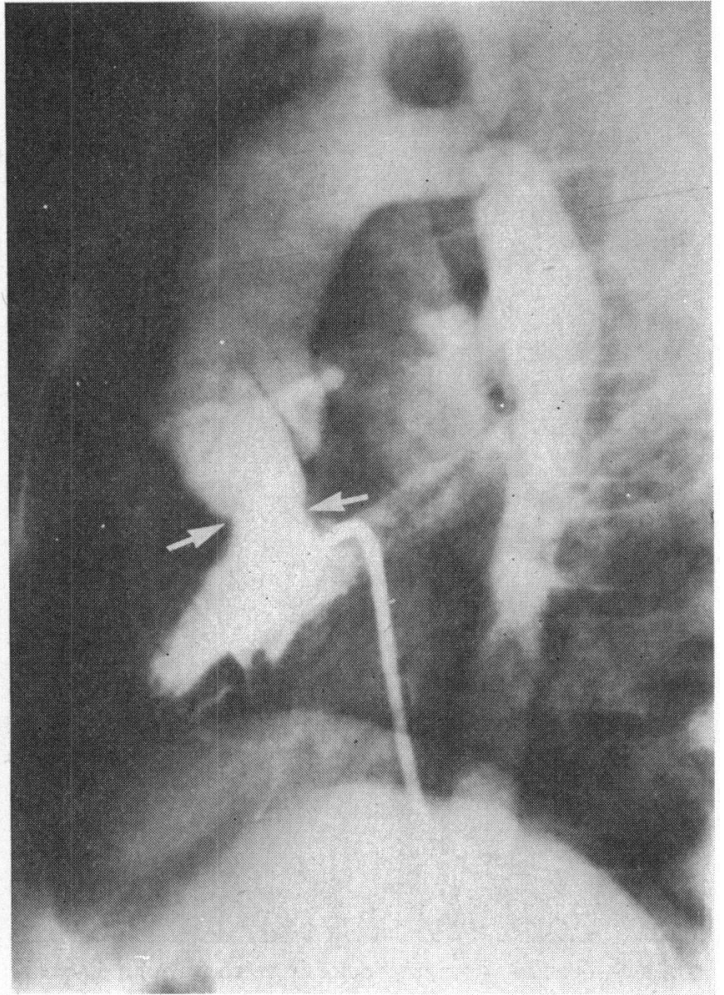

(A)
Fig. 4A.-Lateral left ventricular angiogram in discrete subaortic stenosis. The valve cusps do not open fully during ejection and the narrow jet of blood escaping through the subvalvar stenosis meets the undersurface of an almost closed aortic valve. The frame shown was exposed 0.14 sec. after the $Q$ of the electrocardiogram when the aortic valve would normally be fully open. The gradient in this case was 100 $\mathrm{mm}$. $\mathrm{Hg}$ across the subvalvar stenosis and $35 \mathrm{~mm}$. $\mathrm{Hg}$ across the coarctation.

Fig. 4B.-Frontal view of the same patient; the subaortic obstruction was $2 \mathrm{~cm}$. below the aortic valve and can be seen midway between the aortic valve cusps and the posterior cusp of the mitral valve which is seen outlined in this diastolic film.

Fig. 4c.-Frontal diastolic left ventricular angiogram from another patient showing subvalvar obstruction rather closer to the aortic valve $(1 \mathrm{~cm}$. beneath it). The aortic sinuses were dilated but the cusps were normal. The mitral valve was thickened and slightly narrow but competent. The levels of the aortic valve cusps, the subaortic obstruction, and the posterior mitral valve cusp are arrowed in both Fig. $4 \mathrm{~b}$ and 4c. This patient had had a coarctation resected in infancy. There was no gradient across the coarctation site but a gradient of $160 \mathrm{~mm}$. $\mathrm{Hg}$ across the subvalvar obstruction.

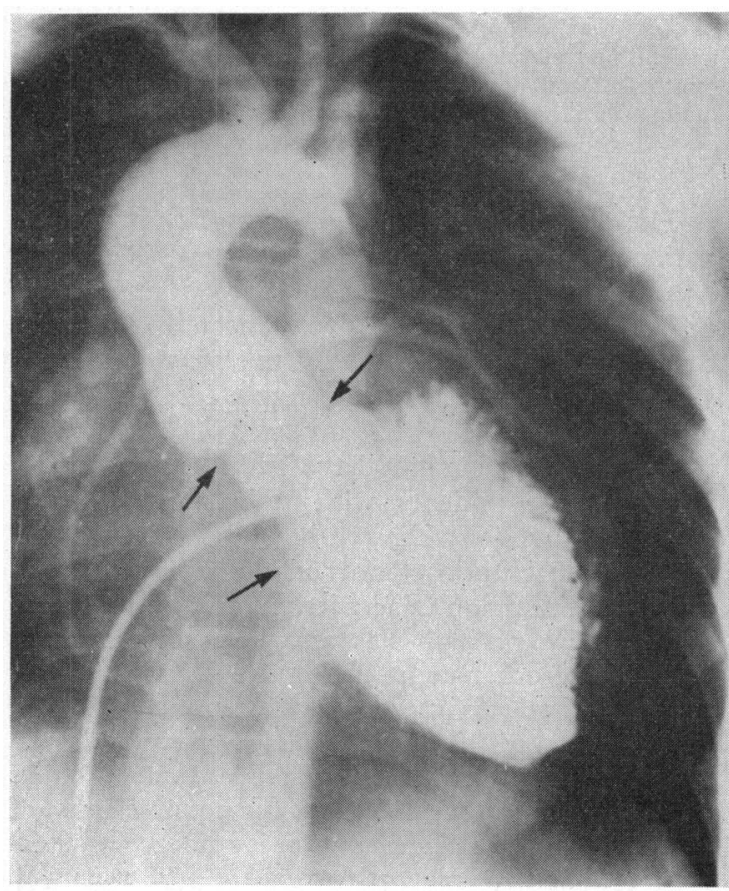

(B

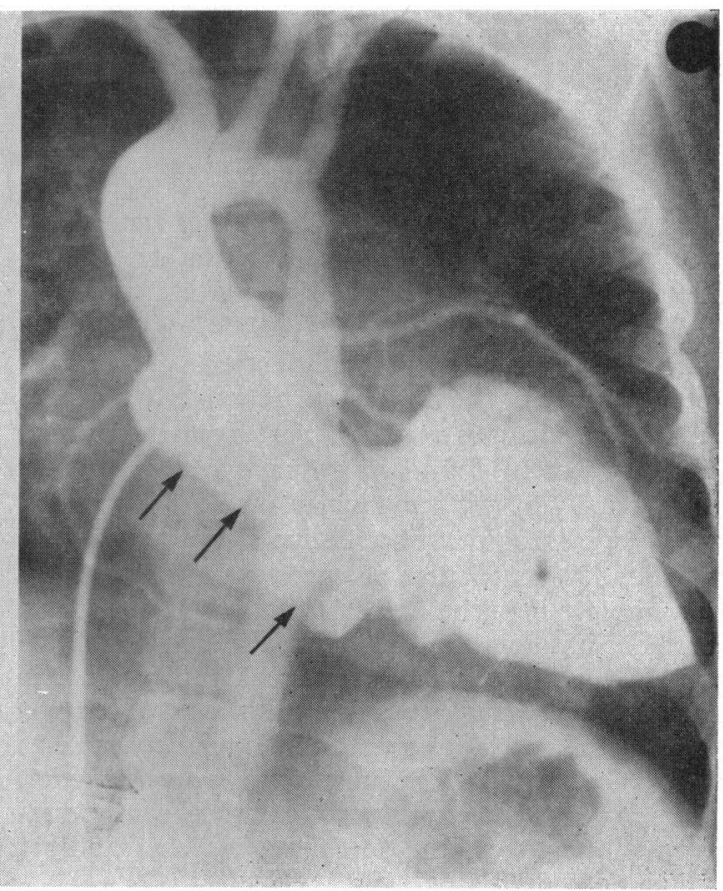

C) 


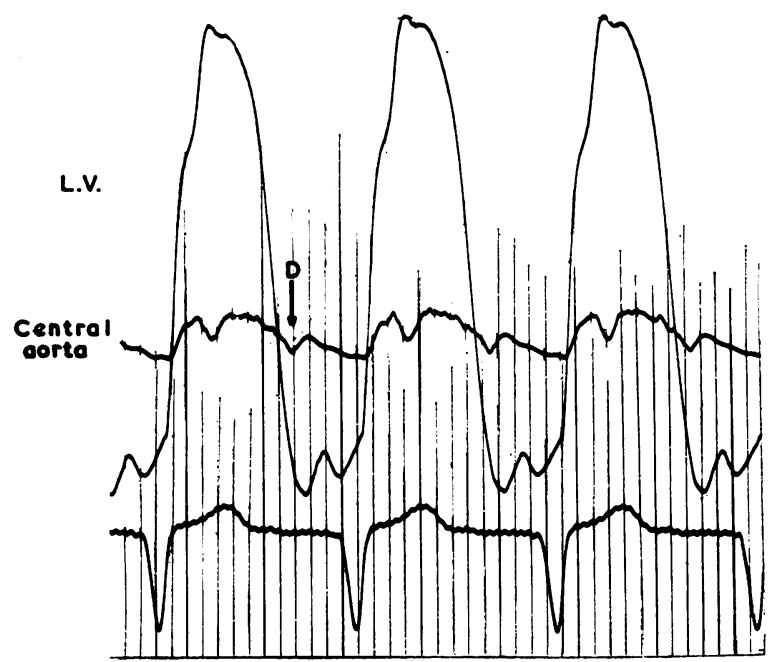

Fig. 5.-Central aortic and left ventricular cavity pressures from a typical patient with discrete subaortic stenosis. The dicrotic notch (D) is delayed $0.04 \mathrm{sec}$. after the pressure crossover. During this time there will be reflux of aortic blood into the left ventricle.

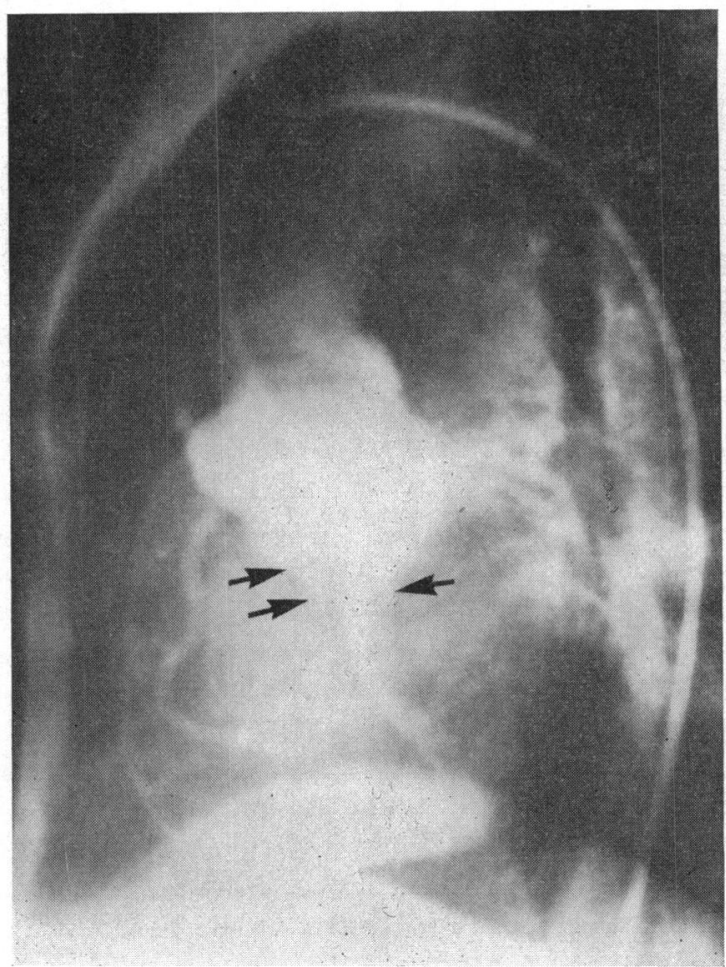

(A)

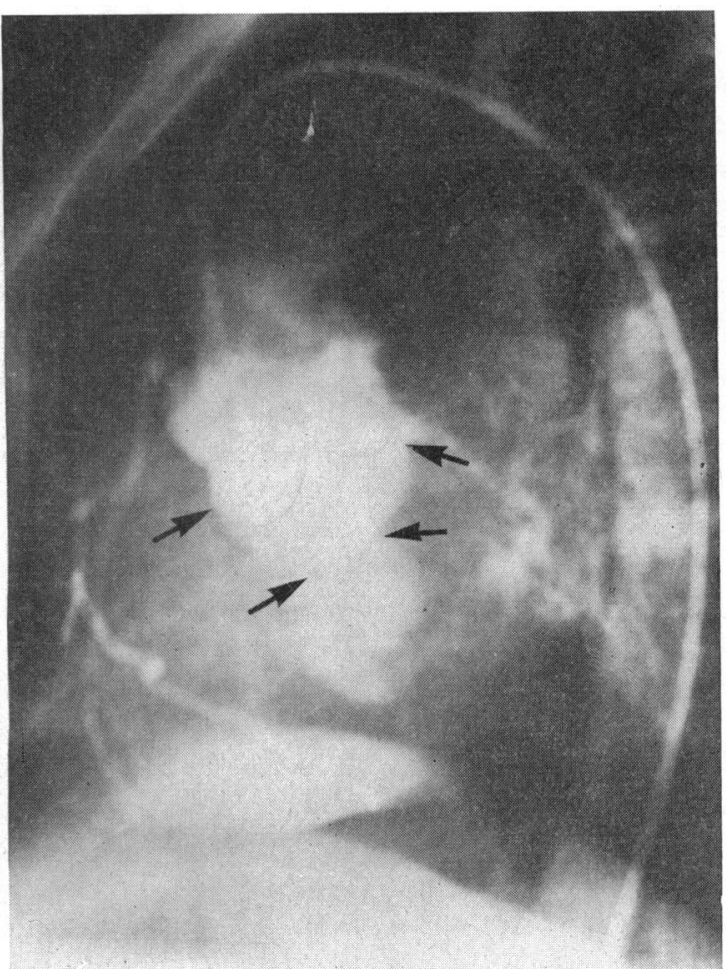

(B)

Fig. 6.-Aortogram of the patient whose left ventricular angiogram is shown in Fig. 4C. Fig. 6A lateral view in diastole, Fig. 6B lateral view in systole. There is sufficient aortic incompetence to outline the subvalvar obstruction. The aortic sinuses are dilated and distorted but the obstruction is well below them. Level of aortic cusps and subvalvar obstruction are arrowed. 

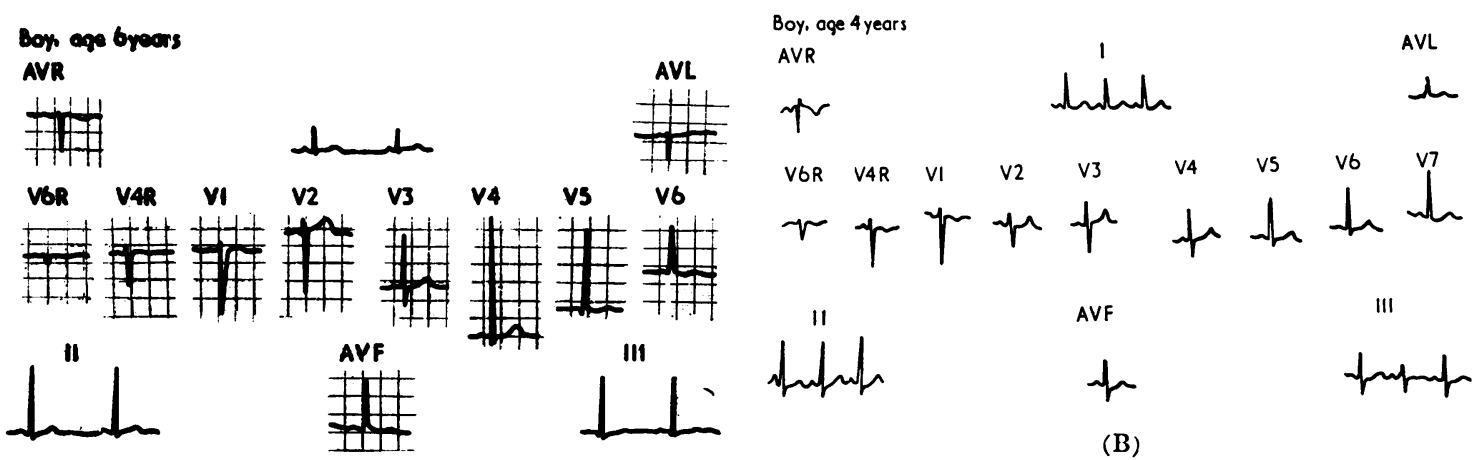

(A)

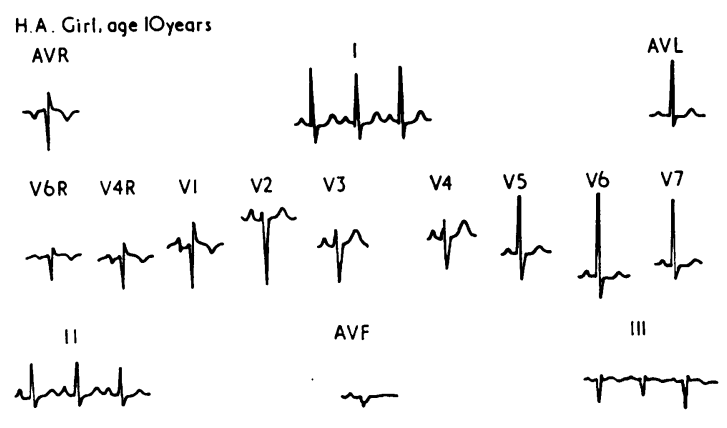

FIG. 7.-(A) The normal electrocardiogram from a 6-year-old boy with congenital aortic valve stenosis and no gradient across the valve under resting conditions. Such high voltage is common in children but is often mistakenly attributed to left ventricular hypertrophy. Above is the electrocardiogram of (B) a 4-year-old boy, and left (C) a 10-year-old girl with discrete subaortic stenosis and gradients of respectively 150 and $160 \mathrm{~mm}$. $\mathrm{Hg}$ across the obstruction. Both might be considered to be normal.

(C)

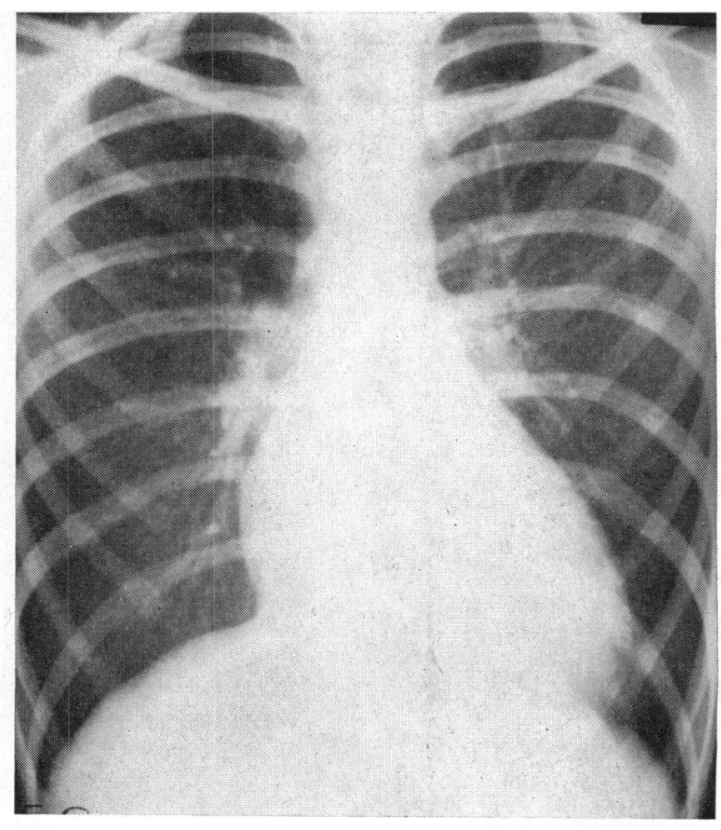

(A)

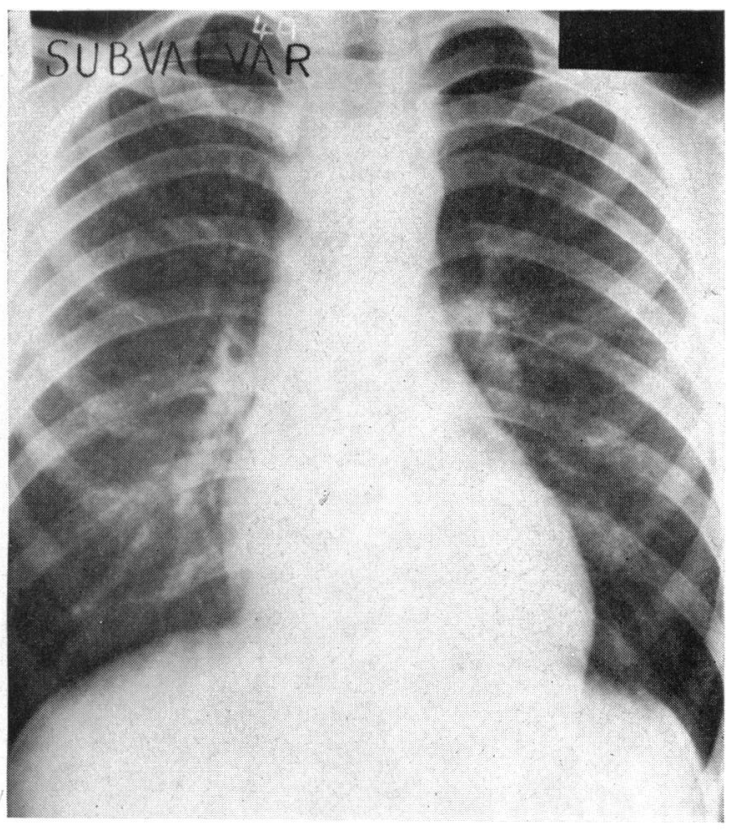

(B)

FIG. 8.-Postero-anterior radiographs of the chest from a 10-year-old girl with severe aortic valve stenosis (A) and from a 14-year-old boy with discrete subvalvar stenosis (B). The aorta is only dilated in the patient with subvalvar stenosis. The left ventricle is obviously enlarged in (A) (gradient $150 \mathrm{~mm}$. $\mathrm{Hg}$ ) but not in (B) (gradient $110 \mathrm{~mm} . \mathrm{Hg}$ ). 
Aortic valve stenosis < age 20 years

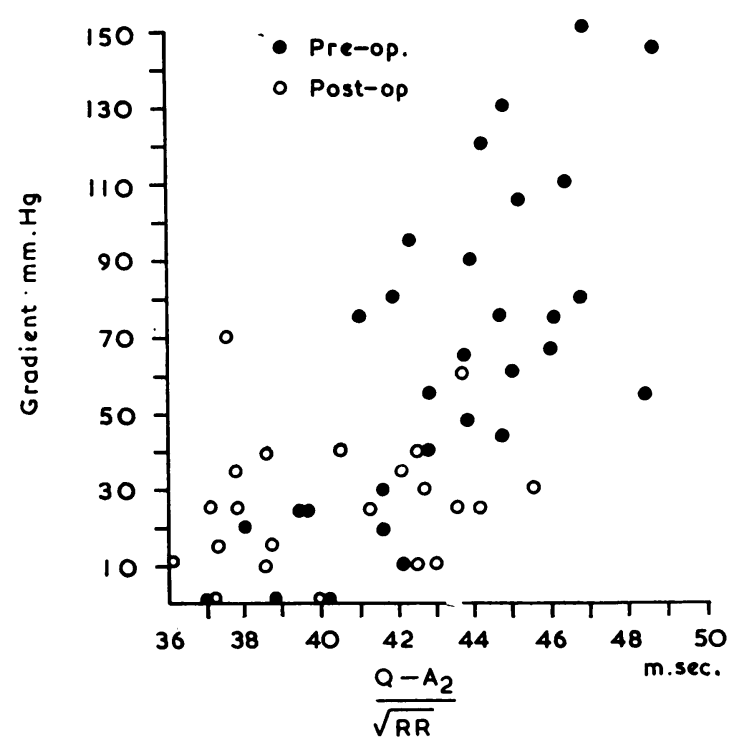

(A)

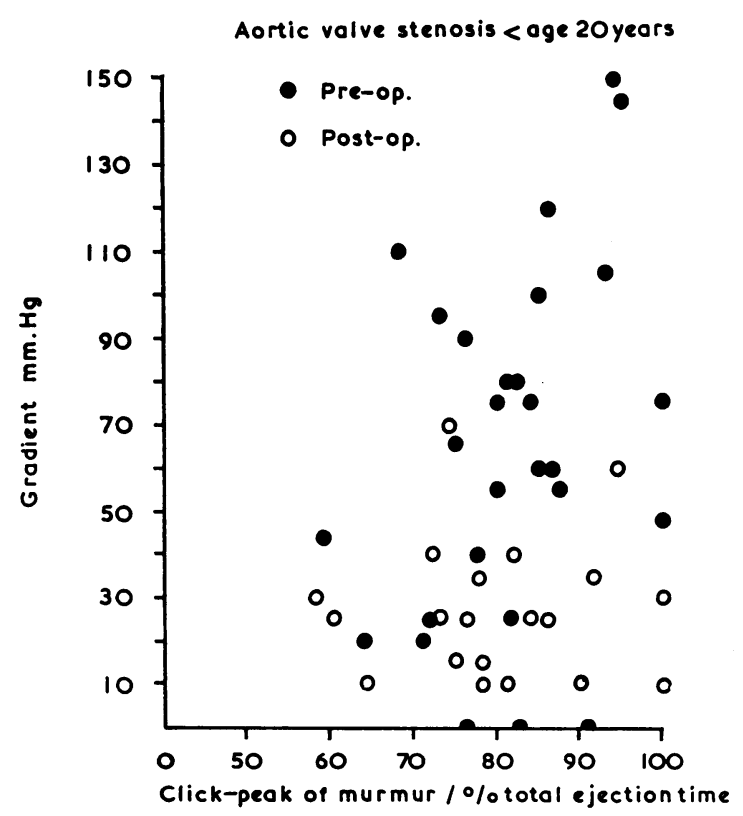

(B)

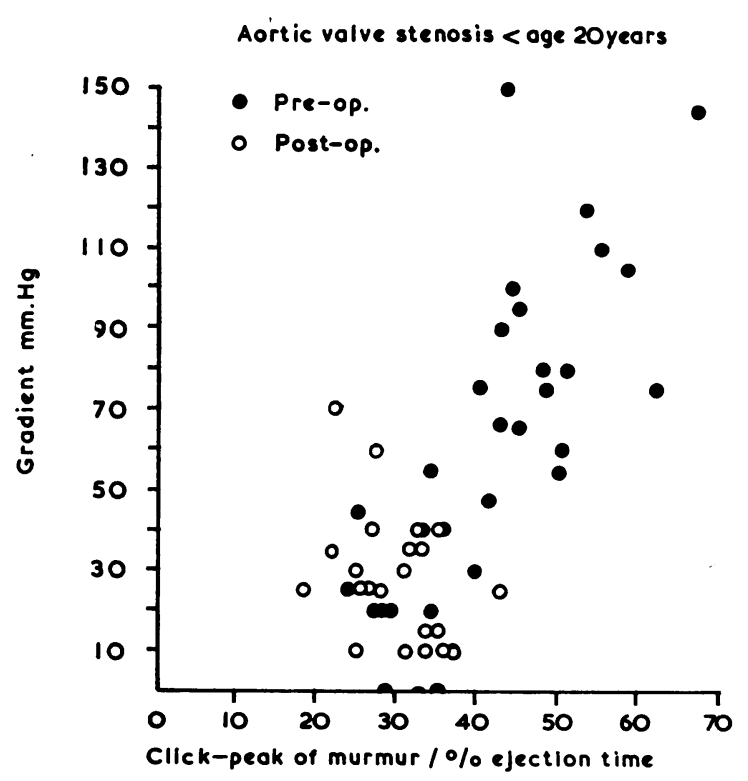

(C)

Fio. 9.-(A) The duration of left ventricular systole $\left(\mathrm{Q}-\mathrm{A}_{2}\right)$ corrected for cycle length $\left(Q-A_{2}\right)$ plotted against the aortic valve gradient; there was no correlation. (B) The length of the murmur also gave no indication of severity. (C) The time of maximum intensity of the murmur was later in patients with more severe stenosis. 
marked in four of our patients, but in the others there seemed no possibility that the cusps might have failed to meet normally through this cause. The aortogram of one patient with a grotesque dilatation of the aortic sinuses and aortic root is shown in Fig. 6, and it did seem likely that her rather severe aortic incompetence was related to dilatation of the aortic ring; the valve cusps themselves were normal. This patient had had a coarctation of the aorta resected in infancy and high pressure in the central aorta may have originally been a contributing factor to this excessive dilatation. Coarctations were also present or had been previously resected in 5 other patients with discrete subaortic stenosis, but in only one of the 5 was dilatation of the aortic root especially marked.

Mechanical distortion of the normal valve has also been invoked as a cause of valve incompetence in subaortic stenosis through impingement of the subaortic diaphragm on the dependent convexity of the closed valve cusps. In only one of our patients was the subaortic stricture sufficiently close up underneath the valve for this to have occurred; in the others the obstruction was usually 1 to $2 \mathrm{~cm}$. below the valve (Fig. 4A, 4B, 4C).

A further possibility is that the early diastolic murmur originates at the subvalvar obstruction. Although retrograde aortography proves that the valve itself is incompetent in these cases, it is possible that the continuation of the murmur does indeed arise below the valve which closes and presumably becomes competent about $0.04 \mathrm{sec}$. after the cross-over of left ventricular aortic pressures. The regurgitant murmur might, therefore, be expected to be short, but it is in fact indistinguishable from the murmur in other cases of aortic incompetence. This may be because the regurgitant volume is too great to be contained within the subvalvar chamber, and its passage through to the body of the ventricle may become audible, particularly in cases with more severe obstruction. Intracardiac phonocardiographic records could clarify this point.

If the thesis of a delay in the transmission of left ventricular pressure changes through the subvalvar obstruction to the valve is a correct one, normal valve function with an audible aortic second sound and loss of aortic incompetence should follow successful operation. However, the subvalvar obstruction in these patients is part of a complex abnormality in the structure of the left ventricle with the subvalvar diaphragm forming only one component of the obstructing ring which is completed by the aortic cusp of the mitral valve itself, the bulging hypertrophied interventricular septum and much fibromuscular overgrowth. Both the integrity of the mitral valve and of the conducting tissue may be prejudiced, and, in consequence, it is usually not possible to relieve the obstruction completely. Only one of our patients has completely lost all obstruction; he has no residual post-operative gradient 5 years after operation, aortic closure is audible and not delayed, and the valve is competent. Most patients have significant residual obstruction and the auscultatory findings have not changed compared with those before operation.

\section{SUMMARY}

Discrete subvalvar aortic stenosis is distinguished from non-calcific valvar aortic stenosis by the absence of an early systolic ejection click and by a soft or inaudible aortic valve closure sound. These auscultatory characteristics closely resemble those of calcific aortic valve stenosis and it has been shown that immobility of the valve is the basis for its silence in each group. It is postulated that the poor valve movement in discrete subaortic stenosis is due to the pressure baffle imposed by the subvalvar obstruction. Persistence of the subvalvar obstruction in the relaxing ventricle is responsible both for the softness of aortic valve closure and for incompetence of the valve. It is suggested that the early diastolic murmur in such cases is started by blood refluxing through the valve and continued by the same blood refluxing through the subvalvar stenosis. In valvar aortic stenosis, as in mitral stenosis, loud aortic valve opening and closure sounds indicate that the cusps are mobile, and, as in mitral stenosis, the sounds disappear when the valve calcifies in later life.

The most reliable criterion of severity in fixed aortic stenosis was found to be the position of the peak of the murmur in relation to its duration. A murmur with an early peak indicated mild stenosis regardless of its duration, whereas a delayed maximum intensity could be correlated with more severe obstruction.

We would like to thank Professor J. F. Goodwin for constructive criticism, and gratefully acknowledge the help of Mrs. Phyllis Sym who prepared the illustrations.

\section{REFERENCES}

Arrigalla, F. C., and Taquini, A. C. (1941). Chasquido de apertura de las sigmoideas pulmonares. Rev. argent. Cardiol., 8, 43.

Braunwald, E., Goldblatt, A., Aygen, M. M., Rockoff, S. D., and Morrow, A. G. (1963). Congenital aortic stenosis. I. Clinical and hemodynamic findings in 100 patients. Circulation, 27, 426.

Braverman, I. B., and Gibson, S. (1957). The outlook for children with congenital aortic stenosis. Amer. Heart $\mathfrak{f}, \mathbf{5 3}, 487$. 
Dotter, C. T., Bristow, J. D., Menashe, V. D., Starr, A., and Griswold, H. E. (1961). Stenosis of left ventricular outflow tract. Causes and contrast visualization. Circulation, 23, 823.

Engle, M. A., and Ehlers, K. H. (1964). Auscultation and phonocardiography in the recognition and differential diagnosis of congenital aortic stenosis. In The Theory and Practice of Auscultation, The Ninth Hahnemann Symposium, ed. B. L. Segal, W. Likoff, and J. H. Moyer, p. 238. F. A. Davis, Philadelphia.

Epstein, E. J., Criley, J. M., Raftery, E. B., Humphries, J. O., and Ross, R. S. (1965). Cineradiographic studies of the early systolic click in aortic valve stenosis. Circulation, 31, 842.

Gamboa, R., Hugenholtz, P. G., and Nadas, A. S. (1964). Accuracy of the phonocardiogram in assessing severity of aortic and pulmonic stenosis. Circulation, 30, 35.

Hancock, E. W. (1961). Differentiation of valvar, subvalvar and supravalvar aortic stenosis. Guy's Hosp. Rep., $110,1$.

Kjellberg, S. R., Mannheimer, E., Rudhe, V., and Jonsson, B. (1959). Diagnosis of Congenital Heart Disease, 2nd ed. The Year Book Publishers, Chicago.

Leatham, A., and Vogelpoel, L. (1954). The early systolic sound in dilatation of the pulmonary artery. Brit. Heart $\mathcal{F}$, 16, 21.

Lees, M. H., Hauck, A. J., Starkey, G. W. B., Nadas, A. S., and Gross, R. E. (1962). Congenital aortic stenosis. Operative indications and surgical results. Brit. Heart f., 24, 31 .
Minhas, K., and Gasul, B. M. (1959). Systolic clicks: A clinical, phonocardiographic, and hemodynamic evaluation. Amer. Heart F., 57, 49.

Nadas, A. (1957). Pediatric Cardiology. W. B. Saunders, Philadelphia.

Oakley, C. M., Hallidie-Smith, C., and Bentall, H. H. (1964). Aortic valve movement in congenital aortic stenosis. Circulation, 29-30, Suppl. III, p. 134.

Ongley, P. A., Nadas, A. S., Paul, M. H., Rudolph, A. M., and Starkey, G. W. B. (1958). Aortic stenosis in infants and children. Pediatrics, 21, 207.

Raftery, E. B. (1965). A cine-angiographic study of aortic valve dynamics. Brit. Heart f., 27, 286.

Reinhold, J., and Rudhe, U. (1957). Relation of the first and second heart sounds to events in the cardiac cycle. Brit. Heart f., 19, 473.

Reynolds, J. L., Nadas, A. S., Rudolph, A. M., and Gross, R. E. (1960). Critical congenital aortic stenosis with minimal electrocardiographic changes. A report on two siblings. New Engl. F. Med., 262, 276.

Vogel, J. H. K., and Blount, S. G. (1965). Clinical evaluation in localizing level of obstruction to outflow from left ventricle. Importance of early systolic ejection click. Amer. F. Cardiol., 15, 782.

Wolferth, C. C., and Margolies, A. (1945). Heart sounds. In The Diagnosis and Treatment of Cardiovascular Disease, 3rd edn., ed. W. D. Stroud, Vol. 1, pp. 545-592. Davis, Philadelphia. 